УДК 821.161 .1

\title{
B.М. Насртдинова
}

\section{К ВОПРОСУ О ЖАНРОВОМ СВОЕОБРАЗИИ И СИСТЕМЕ ОБРАЗОВ СКАЗКИ А.М. ВОЛКОВА «УРФИН ДЖЮС И ЕГО ДЕРЕВЯННЫЕ СОЛДАТЫ»}

Автор статьи обращается к исследованию широкоизвестного произведения классика детской советской литературы А.М. Волкова, «Урфин Джюс и его деревянные солдаты». Исследуя жанровые особенности произведения и специфику системы образов, мы обнаруживаем такие новаторские приёмы писателя, как замена Протагониста Антигероем, второстепенный характер ролей положительных персонажей, нехарактерную для сказочного текста динамику образов отрицательных героев. Кроме того, в работе отмечается, что, будучи сюжетно интегрирована в цикл произведений об Изумрудном городе, сказка «Урфин Джюс и его деревянные солдаты», с одной стороны, является элементом сиквела, а с другой, в силу своеобразия художественной природы, звучит и как произведение фактически автономное - спин-офф со знакомыми действующими лицами. Произведя литературный, философский, ономастический анализ указанного текста, мы приходим к выводу, что замысел А.М. Волкова гораздо шире, чем принято полагать; что кроме самоочевидной сказочной фабулы, здесь содержатся и социальные, и философские размышления, поданные имплицитно, в символическом ключе, а предполагаемыми реципиентами произведения являются не только дети, но и взрослые.

Ключевые слова: волшебная сказка, социальная сказка, литературная сказка, советская литература, сказочный нарратив, образная система, жанр.

DOI: $10.35634 / 2412-9534-2020-30-6-1078-1084$

Литературная сказка «Урфин Джюс и его деревянные солдаты» - второй эпизод созданного А.М. Волковым цикла-гексалогии о Волшебной стране. На первый взгляд, история честолюбивого столяра - всего лишь «первое среди равных» продолжение «Волшебника Изумрудного города», которое наследует и легенду-background (невероятное путешествие девочки Элли в фургоне, подхваченном ураганом), и систему узнаваемых персонажей, и аксиологические координаты; а также воспроизводит «пространственно-временной континуум» названного нарратива. Однако, при более внимательном рассмотрении этого произведения, становится очевидной его инаковость, отдельность по отношению как к знаменитому тексту-предшественнику, так и к последующим «сериям» волшебной саги. То есть, выражаясь терминами кинематографии, «Урфин Джюс» - не сиквел, а скорее - спинофф оригинального сюжета, а сама сказка, в силу колоссального жанрового потенциала, благодаря извечной своей «невсамделишной вседозволенности», приверженности принципу «anything goes» (животные и птицы разговаривают, неодушевленные предметы оживают, и т. д.) избрана автором в качестве безошибочно безопасного формата трансляции тех идей, реципиентами которых являются не только и не столько читатели младшего школьного возраста.

Анализируя специфику жанровой природы «Урфина Джюса», нельзя не отметить и тот факт, что данная работа не может быть в полной мере отнесена к «волшебным» сказкам, т. е., по выражению В.Я. Проппа, к «сказкам в собственном смысле слова» [9. С. 6]. Текст А.М. Волкова обнаруживает явственное тяготение к традиции социальной сказки - как стилистически-композиционно, так и содержательно. Так же, как и в канонической социальной сказке Ю. Олеши «Три толстяка», в милитаристской повести о дуболомах и их амбициозном создателе происходит эксплуатация сказочного экстерьера и декорума, позволяющая удерживать повествование в русле аллегорически-карнавальной подачи, что, во-первых, снижает градус социального пафоса и драматизма, а во-вторых, сообщает проблемному тексту изящество и грацию, недоступные ни одной из типических «остросоциальных» форм - ни фельетону, ни очерку, ни памфлету. Кроме того, в отличие от т. н. «волшебной сказки», сверхзадачи которой всегда связаны с «прививкой» нравственно-дидактических категорий, сказка социальная апеллирует не к абстрактным человеческим экзистенциалам («Добро-Зло»), часто деперсонифицированным, или имеющим причудливые инкарнации (Дракон versus рыцарь, злой волшебник versus добрый маг, и проч.) но к свое-временным, часто злободневным явлениям социальногопсихологического и социально-политического характера.

Такими явлениями в работе А.М. Волкова становятся онтологически родственные феномены тирании и диктатуры: в фокусе писательского внимания находятся и конгломерат воспроизводимых 
К вопросу о жанровом своеобразии и системе образов сказки А.М. Волкова...

ими социальных институций, и психологические архетипы самого правителя, которого, кстати, автор эксплицитно именует соответствующим образом («взгляд диктатора» [3. С. 75], «на службе у тирана» [3. С. 138], «вид диктатора был и страшен, и жалок» [3. С. 207]); и его ближайших соратников. Думается, что излишне контекстная политизация и «конспирологические» трактовки изображаемого Волковым социально-политического ландшафта некорректны: автор обращается к вирусному для двадцатого столетия явлению государственного устройства с жесткой вертикалью власти, опирающейся на силовые структуры вообще, а выписанный им образ деспотичного правителя - синтетический, собирательный, не ассоциированный непосредственно с какой-либо исторической фигурой.

Однако, следует признать, что существуют различные точки зрения на этот счёт. Например, П. Петров отмечает, что магистральным мотивом всего социально-фантастического эпоса является испытание героев бременем власти [8], с чем трудно не согласиться; Н.В. Латова в своей работе утверждает, что «борьба за власть между Страшилой, Дровосеком и Урфином Джюсом рисуется не просто как противоборство законных правителей и узурпатора-захватчика, но как схватка «просвещенной монархии и злобной тирании» [5]; а Ю.К. Меркулов и вовсе полагает, что художественное полотно А. Волкова сверхсемиотично и буквально изобилует требующими дешифровки знакамисимволами: так, сведения о занесённых ветром семенах иноземного растения автор полагает намеком на марксизм и научный социализм, подаренный коррумпированному придворному летописцу «серебряный подстаканник, отобранный у одного купца» интерпретирует как очевидную референцию к деятельности Торгсинов, а затем и вовсе, в весьма радикалистском ключе заявляет, что «избавление Зеленой Страны от власти Джюса видится А.М. Волкову в комбинированном усилили черносотенных центров (Чарли Блэк) и восстания опомнившихся жителей внутри страны» [7] - суждение смелое, эмоционально окрашенное, демонстрирующее немалую эрудицию пишущего, однако лишённое хоть сколько-нибудь убедительной и аргументированной доказательной базы. Впрочем, некоторые сюжетные линии, реализованные А.М. Волковым, и впрямь могли быть инспирированы современными ему реалиями: сама собою напрашивается параллель между демонтажем изумрудов с башен и стен города с их последующим поступлением в личную казну Урфина Первого и снятием крестов с храмовых куполов, переплавкой окладов икон и колоколов; процедурами реквизиции церковного имущества вообще.

В то же время, неправомочной и даже кощунственной видится попытка экстраполяции галереи образов деревянных солдат, именующих себя «дуболомами», на институт Советской Армии: на момент создания книги, в 1958 г., Советский воин, воин-Освободитель был в народном сознании безусловным синонимом торжества гуманизма над зверствами фашистов. Такие неоднозначные и болезненные страницы в истории советских Вооруженных Сил, как Новочеркасский расстрел и Пражская весна, произойдут много позже, поэтому ни предвидеть их, ни подразумевать в своём тексте детский писатель Волков, разумеется, не мог.

Но вернёмся к рассмотрению специфики «Урфина Джюса и его деревянных солдат» по отношению к канонике сказочного жанра. Важной отличительной особенностью является нарушение привычной сказочной «расстановки сил», баланса «положительных и отрицательных» героев. Вопервых, в произведении Волкова фактически отсутствует Протагонист в классическом, присущем рассматриваемому жанру смысле. Его место занимает Антигерой, который дольше и эффектнее находится «в кадре» повествования и в которого, посредством ярких изобразительно-выразительных средств, писатель инвестирует большую часть своего внимания. Такая расстановка акцентов может быть свойственна плутовскому роману, нуарному детективу, психологическому триллеру; для сказочного полотна данный ход является новаторским. А.М. Волков не только предоставляет фигуре властолюбивого ремесленника привилегированное право открывать сказочное действо, становясь при этом ключевым его агентом, но и выносит его имя собственное в название второго эпизода волшебной эпопеи, давая понять, что перед нами - персональная, именная история Урфина; в известном смысле, его литературный байопик.

Во-вторых, для сказочной традиции характерен приём изображения злодея в эмоциональной и поведенческой статике: возможности ментальной динамики и нравственной эволюции даруются положительным персонажам, тогда как отрицательные герои часто являются «реквизитом сюжета», фигурой-функцией, отыгрывающей свою одномерно-негативную миссию, необходимую, как правило, для инициации и дальнейшего роста протагониста. «Плохие» действующие лица, в таком случае, оказываются сродни преступникам в парадигме Ч. Ломброзо: примордиально порочные, они не только 
последовательно реализуют свои злокозненные умыслы, но, как правило, ещё и наделены красноречиво-отталкивающей внешностью. Совершенно иных дескриптивных стратегий по отношению к своему заглавному персонажу придерживается А.М. Волков. Писатель словно пытается рассмотреть, чем сформированы болезненная жажда власти, нескрываемая мизантропия и деспотические устремления. Причиной тому оказываются, с одной стороны, вздорный нрав героя («Урфин ещё в детстве отличался сварливым характером» [3. С. 6]), лишь обостренный семейным неблагополучием («Родители Урфина умерли рано...» [3. С. 6]); а с другой стороны - окружающая его действительность: слишком добры и мягкосердечны были Жевуны, «робкие и милые человечки» [3. С. 5], населявшие Голубую страну, слишком безропотно они подчинялись злой волшебнице Гингеме и лишь плакали всякий раз, не смея возразить ни слова. Они настолько привыкли оплакивать своё бедственное положение, что даже обустроились, «оборудовались» для горя: «Головы Жевунов тряслись от неудержимого плача, а бубенчики под шляпами подняли радостный трезвон. Этот трезвон так не подходил к мрачному настроению Жевунов, что они сдёрнули свои шляпы и повесили их на специально врытые у крылечек столбики» [3. С. 42] ${ }^{1}$. Таким образом, писатель подчеркивает, что фактором, провоцирующим укоренение тиранических властных практик, может быть и «психология жертвы», превалирующая в массовом сознании социума. А.М. Волков неоднократно замечает, что Урфин - искусный столяр, человек небесталанный, однако совокупность названных факторов приводит к мутации, «озлокачествлению» черт его личности. Кроме того, вчерашний ремесленник, ставший правителем - живое воплощение принципа «кто был ничем - тот станет всем», а итоги его правления убедительно демонстрируют, что происходит в том случае, если кухарка начинает управлять государством.

Симптоматичен и ономастический анализ, т. е. обращение к «герменевтике» имени собственного заглавного героя. «Урфан» (а именно так первоначально планировал «наречь» своего персонажа А.М. Волков [Цит. по 8], - фактически прямая, калькирующая транслитерация английского существительного 'orphan' - сирота. Это, как мы знаем, всецело коррелирует с биографией столяра; таким образом, first name в рассматриваемом антропониме выполняет констатирующие функции. Оценочной, пожалуй, может быть названа вторая его часть, фамилия, given name - Джюс. Наиболее распространённой, с отсылкой к дневниковым записям автора (Цит. по: [1]), является версия о том, что Джюс - не что иное, как авторский дериватив английского прилагательного jealous, т. е. завистливый, ревнивый. В самом деле, зависть к мирному, идиллически-простодушному счастью Жевунов вполне могла стать пусковым механизмом, триггером злокозненных планов Урфина; такая фамилия персонажа позволяет читателю делать вывод о психологической мотивации героя. Впрочем, следует отметить, что, будучи наиболее популярной, версия, изложенная выше, не является единственной: для семейства голландских и фламандских мужских имён характерно имя Джус, имеющее значение «преумножающий» [4]. Был ли об этом осведомлён А.М. Волков, доподлинно неизвестно, однако персональная характеристика «преумножающий» не противоречит свойствам личности персонажа: Урфин трудолюбивый, упорный, способный, обладает созидательными навыками (столярное дело), но, поддавшись искушению властью, сворачивает с верного пути, и преумножает уже хаос, угнетение, страх.

Вторым по значимости действующим лицом литературной сказки А. Волкова являются, вопреки обманчивому впечатлению, не Элли и её товарищи, а созданные Урфином деревянные солдаты. Может сложиться ошибочное мнение, что карикатурная манера изображения «дуболомов» свидетельствует о негативистском отношении писателя к социальному институту армии вообще - и солдаты, и их командиры показаны ограниченными и агрессивными: «Работники быстро распилили брёвна, и так как дела больше не оказалось, они принялись пилить всё, что попадалось под руку...четверо с бессмысленным усердием пилили друг другу ноги!» [3. С. 34], «Клинья вылетели, и пальцы оказались намертво защемлёнными. Дуболом понапрасну дергал их, а потом, чтобы освободиться, обрубил себе пальцы левой руки» [3. С. 36]. Вместе с тем, наряду с откровенной иронией по поводу примитивного устройства и мышления дуболомов, к тексте содержатся и замечания иного характера: деревянные солдаты не лишены таких сложных нравственных переживаний, как стыд («- Нам стыдно... - смущенно ответил Лан Пирот. - Мы - голые...» [3. С. 42]), задаются вопросами о высших экзистенциях («- А что такое смерть?» [3. С. 62]), но - «слишком мало видели за свою короткую жизнь» [3. С. 52]. Первоначальная иронично-обличительная интонация А. Волкова, таким образом, перемежается если не с сочувствующей, то с явно эмпатийной: солдаты отнюдь не плохи сами по се-

\footnotetext{
${ }^{1}$ Курсив мой. - B.M.
} 
К вопросу о жанровом своеобразии и системе образов сказки А.М. Волкова...

бе, а этос военной службы амбивалентен: призванная обеспечивать силу государственного принуждения, армия, в то же время, может оказываться заложницей многокомпонентной диалектики социальных процессов, что неоднократно доказывала история прошлого, двадцатого столетия.

Как уже было сказано выше, для Урфина его создатель не жалеет ни «экранного времени», ни ярких красок к портрету. Условные протагонисты - Элли и компания, наоборот, находятся в расфокусе писательского видения, и выписаны либо бегло, пунктирно (как сама Элли), либо нарочито неправдоподобно, как Чарли Блэк. Но если дочь канзасских фермеров с её неявленным характером, отсутствием выдающихся способностей или запоминающихся привычек, не обременённая вложенными в её уста программными для произведения цитатами и являющаяся, фактически, неким «свадебным генералом», гарантом «сериальности» повествования, обеспечивающим «закольцованность» сюжетных линий, есть просто хорошая девочка в усредняющем, статистически-стандартизированном значении этого определения, что образ дядюшки Чарли, старого морского волка, куда более любопытен. Имидж бывалого моряка и его биография замешаны на избыточной, утрированной флибустьерской романтике в духе раннего Э. Багрицкого: здесь и непременная деревяшка вместо ноги, и знакомство с племенем аборигенов-людоедов, и многочисленные эмфатические восклицания, которыми наполнена его речь («Клянусь якорем! - воскликнул он» [3. С. 106], «Мачты и паруса! - взревел моряк» [3. С. 106], «клянусь всеми черепахами Куру-Кусу» [3. С. 101]). Для полноты антуража не хватает только говорящего попугая на плече; впрочем, его с легкостью заменяет словоохотливая ворона Кагги-Карр.

А.М. Волкову нельзя отказать ни в безупречном писательском вкусе, ни в чувстве меры; подтверждением тому служит и то, что «Волшебник изумрудного города» в том виде, в котором он известен российскому читателю, является не дублирующим переводом текста «The Wizard of Oz», но и оригинальной его переработкой, и концептуальной авторской вариацией на заданную тему, и своего рода римейком с поправкой на «региональный компонент». Сам автор указывает, что «многое в сказке Фрэнка Баума он изменил, написал новые главы» [2. С. 187], а И.П. Лупанова отмечает, что у А.М. Волкова «моральный конфликт добра и зла, составляющий основу волшебно-сказочных сюжетов, оборачивается конфликтом сил социально враждебных... В акцентации этой стороны и проявилась основная творческая работа советского сказочника над чужой книгой» [6. С. 27]; тем самым ставя в заслуги автору проработку и усиление социальной проблематики в работе. Кроме того, дневниковые записи писателя позволяют сделать вывод о том, что ему были присущи чёткие представления о разумной достаточности, уместности и умеренности художественного текста: так, при анализе последующих эпизодов озианы, принадлежавших перу Баума, А.М. Волков отмечает, что они - ни что иное, как «высасывание из пальца неумных небылиц и придумывание пёстрой толпы людей и чудовищ - деревянных, медных, тряпичных, пряничных, тыквоголовых и т. д. и т. п. Какая чепуха! Если не сдерживать себя, как Баум, определенными литературными рамками, я могу писать таких «сказок» по шести в год!» (Цит. по [1]). В таком случае, становится очевидным, что излишне стилизованный, нарочито хрестоматийный образ Чарли Блэка также работает на воплощение писательского замысла: в противовес жизнеподобию и реалистической интонации в изображении характера Урфина Джюса, персонаж Чарли Блэк очевидно сказочен.

Отдельного внимания заслуживают и образы «сподвижников» Урфина Джюса. Наиболее приближенными к деспотичному правителю оказываются карлик-клоун, в первой редакции безымянный, а позднее наречённый Эотом Лингом, филин Гуамоколатокинт, чье вычурно-аристократическое имя столяром-военачальником было кастомизировано до «Гуамоко», и простодушный медведь Топотун. Очевидно, что все три персонажа - не что иное, как сказочный парафраз образов трёх классических представителей королевского окружения - шута, мудреца-советника и начальника королевской стражи соответственно. Неоднократно они воспроизводятся в мировой литературе, например, в произведениях В. Шекспира, А. Дюма, М. Дрюона. Но если в работах названных авторов эти образы являются богатыми, сложносоставными, порой противоречивыми, то у А. Волкова они максимально упрощены, каждый персонаж воплощает одну, максимум две личностных характеристики: филин мудр, но далёк от почтительных чувств к своему покровителю, относится к нему едва ли не снисходительно, и, фактически, является приспособленцем, согласившись на сделку с Урфином из соображений собственного удобства; клоун немотивированно агрессивен, а медведь - восторженно-наивен. Такая симплификация - не только результат того, что А. Волков отдаёт должное «форматным» требованиям жанра сказки, но и намеренная демонстрация того, как «мутируют», искажаются психотипы и социальные роли в среде, порождаемой авторитарной властью. 
Для произведений А.М. Волкова характерно пересечение линейного и нелинейного пластов повествования: с одной стороны, в силу того, что герои «кочуют» из произведения в произведение, логика их судеб раскрывается последовательно, в сериальной манере. С другой стороны, каждое вновь появляющееся произведение читается не только как строгое продолжение единого гомогенного сюжета, но и как вариация на тему, этюд в пространстве допущения; сюжетные линии оказываются связаны друг с другом не в директивно-ригидном ключе, но эйдетически-пунктирно, «по мотивам». Достигается этот эффект во многом благодаря тому, что в произведении-хедлайнере характеры подаются в своих экстремумах, предельных, наивысших, а значит - наиболее интересных точках бытования. Таков Джеймс Гудвин в «Волшебнике Изумрудного города», таков и Урфин Джюс в широкоизвестной сказке о нём и его деревянных солдатах. Двойственное чувство оставляет краткая встреча с некогда «Великим и Ужасным» на страницах второго эпизода волшебной эпопеи: бывший правитель оказывается заурядным обывателем, держателем бакалейной лавки, и от дальнейшего продолжения приключений, вопреки законам сказочного жанра, отказывается наотрез: «- Нет, не поеду! Хватит с меня волшебников, волшебниц и всяких волшебных дел!» [3. С. 108]. Неоднозначность этого появления заключается в том, что это, по сути, не полноправное действующее лицо, а аватар действующего лица из предыдущего произведения, призванный воплощать горький, но крайне жизнеподобный посыл: «Волшебника Изумрудного города из меня не вышло, придётся переквалифицироваться в бакалейщики». Несомненно, звёздный час мистера Гудвина пришёлся на первую работу А.М. Волкова; детская аудитория читателей знает, помнит и любит его именно таким. Логичным в данном контексте выглядит вопрос о том, насколько, в таком случае, введение данного персонажа в ткань повествования «Урфина Джюса...» целесообразно вообще, а тем более - поданное в свете столь явной развенчанности, разоблачённости сказочного начала. Обоснование этого появления связывается нами со следующими факторами. Во-первых, встреча с полюбившимся героем приятна для читателя, поскольку позволяет вновь испытывать спектр положительных переживаний. Здесь А. Волков демонстрирует понимание значительного психо-эмоционального и коммерческого ресурса ностальгии, а также, фактически, предвосхищает такой мировой тренд массовой культуры, как литературная франшиза, т. е. многократная мультипликация работ и произведений, в которых задействован персонаж, ставший культурным брендом - это и «бондиана» Я. Флеминга, и «поттериана» Дж.К. Роулинг, и многие другие серии произведений. По своим масштабам то явление, которое мы называем литературной франшизой, уступает разве что другой родственной тенденции - франшизе кинематографической, «бесконечным» мыльным операм, сериалам (например «Санта-Барбара» (9 сезонов, 2137 серий), «Улицы разбитых фонарей» (16 сезонов, 501 серия), и даже полнометражным лентам (например, «Форсаж», «Такси»). Во-вторых, как уже говорилось, «Урфин Джюс и его деревянные солдаты» - сложный жанровый гибрид на стыке волшебной и социальной сказок, а значит, адресатами книги являются не только дети, но и взрослые. Это для них бывший волшебник, чье имя внушало восхищение и трепет, появляется в обличье лавочника, напрочь утратившего дух авантюризма, охваченного, по формулировке В. Маяковского, «позорным благоразумием»: sic transit gloria mundi, и яркое прошлое никому ещё не гарантировало столь же удивительного будущего. Аналогично и появление Урфина Джюса в «Огненном боге Марранов», и уж тем более - в «Жёлтом тумане»: десять лет затворничества, ещё одна бесславная попытка узурпации власти, позорное изгнание, а затем - и вовсе пряничный happy-end в лучших традициях советской педагогики: вчерашний стяжатель власти добровольно решает стать простым огородником; злодей не уничтожен, а перевоспитан. Перед нами вновь аватар Урфина Джюса, ведь в целом, его история написана ещё в «деревянных солдатах», а их открытый финал по силе художественного воздействия превосходит предложенные в последующих частях альтернативы: «- Друзья, - сказал Чарли Блек, - а не лучше ли оставить этого человека просто наедине с самим собой? - Правильно, - сказала Элли, - это будет самым тяжелым наказанием для него, пусть он поживёт среди тех людей, которых хотел подчинить себе, пусть всё напоминает ему о его ужасных намерениях и делах» [3. С. 225].

Таким образом, мы приходим к выводу, что смысловой ареал «Урфина Джюса и его деревянных солдат» гораздо шире, чем семантическое поле сказки для детей в традиционном понимании; данная работа содержит богатый материал для анализа и интерпретации, и может быть рассмотрена как в качестве примера социальной сказки наряду с произведениями К. Коллоди, Дж. Родари, Ю. Олеши, так и - наряду с текстами И. Ильфа и Е Петрова - в качестве примера книги с зашифрованными, подразумеваемыми социальными идеями и проекциями. 


\title{
СПИСОК ИСТОЧНИКОВ И ЛИТЕРАТУРЫ
}

1. Александр Волков: Настоящий волшебник Изумрудного города [Электронный ресурс]: URL: https://zen.yandex.ru/media/soyuz/aleksandr-volkov-nastoiascii-volshebnik-izumrudnogo-goroda59df67eb9b403c11 cb7ec6e4 (дата обращения: 04.07.2019)

2. Волков А.М. Волшебник изумрудного города. М.: Советская Россия, 1960 г. 190 с.

3. Волков А.М. Урфин Джюс и его деревянные солдаты. М.: Советская Россия, 1964 г. 236 с.

4. История происхождения и толкование имени Джус [Электронный pecypc]: http://znachenie-tajna-imeni.ru/ znachenie-imeni-Dzhus/ (дата обращения: 04.07.2019)

5. Латова Н.В. Чему учит сказка? (О российской ментальности) [Электронный pecypc]: http://contrlist.ucoz.ru/ Ohta-Center/Tom8/chemu_uchit_skazka-n.v.latova.pdf (дата обращения: 04.07.2019)

6. Лупанова И.П. Быть человеком! (Размышления о герое современной литературной сказки) // Детская литература, 1971. М.: Детская литература, 1971. С. 24-33.

7. Меркулов Ю.К. Двести лет вместе [Электронный ресурс]: https://oboguev.livejournal.com/5971481.html (дата обращения: 04.07.2019)

8. Петров П. «Стратегии сказочности» в первых повестях А.М. Волкова о «Волшебной стране» (к 125-летию писателя) [Электронный ресурс]: Информационный портал «Питер One». URL: http://www.piter1.info/ strategiiskazochnosti-v-pervyih-povestyah-a-m-volkova-o-volshebnoy-strane-k-125-letiyu-pisatelya/ (дата обращения: 04.07.2019)

9. Пропп В.Я. Морфология сказки / Гос. ин-т истории искусств. Л.: Academia, 1928. 152 с. (Вопр. поэтики; Вып. ХІІ).

Поступила в редакцию 27.04.2020

Насртдинова Валентина Михайловна, кандидат философских наук, доцент кафедры иностранных языков ФГКВОУ ВО «Казанское высшее танковое командное ордена Жукова, краснознаменное училище» 420059, Россия, г. Казань, ул. Оренбургский тракт, 6

E-mail: vmnasrtdinova@mail.ru

\section{V.M. Nasrtdinova \\ ON GENRE ORIGINALITY AND IMAGE SYSTEM IN ALEXANDER M. VOLKOV'S FAIRYTALE "URFIN JUS AND HIS WOODEN SOLDIERS"}

\author{
DOI: $10.35634 / 2412-9534-2020-30-6-1078-1084$
}

Within the framework of the present article, the author refers to the study of the well-known work, written by the classic of the Soviet children's literature A.M. Volkov, "Urfin Jus and his wooden soldiers". Investigating genre peculiarities of the book and the specifics of its image system, the author manages to find out such innovative methods of A. Volkov, as the substitution of Protagonist by Antihero, collateral nature of the positive characters' roles and dynamics of the negative heroes' images, which is not inherent to a fairy text. Apart from that, it is being highlighted in the paper that, being masterfully integrated into the cycle of books about the Emerald city (Izumrudniy gorod) in terms of plot, "Urfin Jus and his wooden soldiers" is, on the one hand, the element of sequel, and, on the other - practically an autonomous work, a spin-off with familiar actors. Having carried out a literary, philosophical, onomastic analysis of this text, the author arrives to the conclusion that the original concept of A.M. Volkov is much broader than it is commonly believed; that besides the self-evident fairy-tale storyline, it contains both social and philosophical reflections, submitted implicitly, in a symbolic way, and the presumed recipients of the fairy tale are not only children, but adults as well.

Keywords: fairy tale, social fairy tale, literary tale, Soviet literature, fairy tale narrative, image system, genre.

\section{REFERENCES}

1. Aleksandr Volkov: Nastoyashchij volshebnik Izumrudnogo goroda [Alexander Volkov: the genuine wizard of the Emerald city] URL: https://zen.yandex.ru/media/soyuz/aleksandr-volkov-nastoiascii-volshebnik-izumrudnogogoroda-59df67eb9b403c11cb7ec6e4 (in Russian).

2. Volkov A.M. Volshebnik izumrudnogo goroda. [The Wizard of the Emerald City]. Moscow, Sovetskaya Rossiya Publ., 1960. 190 p. (in Russian).

3. Volkov A.M. Urfin Dzhyus i ego derevyannye soldaty. [Urfin Jus and his wooden soldiers]. Moscow, Sovetskaya Rossiya Publ., 1964. 236 p. (in Russian). 
4. Istoriya proiskhozhdeniya i tolkovanie imeni Dzhus [The history of origination and interpretation of the name Jus]. URL: http://znachenie-tajna-imeni.ru/znachenie-imeni-Dzhus/ (in Russian).

5. Latova N.V. Chemu uchit skazka? (O rossijskoj mental'nosti) [What does a fairytale teach? (With respect to the Russian mentality)]. URL: http://contrlist.ucoz.ru/Ohta-Center/Tom8/chemu_uchit_skazka-n.v.latova.pdf (in Russian).

6. Lupanova I.P. Byt' chelovekom! (Razmyshleniya o geroe sovremennoj literaturnoj skazki) [To be a human! (Reflections about the hero of a modern literary tale)]. Moscow, Detskaya literature Publ., 1971. pp. 24-33. (in Russian).

7. Merkulov Yu.K. Dvesti let vmeste [Two hundred years together]. URL: https://oboguev.livejournal.com/ 5971481.html (in Russian).

8. Petrov P. «Strategii skazochnosti» v pervyh povestyah A.M. Volkova o «Volshebnoj strane» (k 125-letiyu pisatelya) [The fairytale strategies in the first novels by A.M. Volkov about the "Magic Land" (to the 125-th anniversary of the writer)]. URL: http://www.piter1.info/strategii-skazochnosti-v-pervyih-povestyah-a-m-volkova-o-volshebnoy-strane-k125-letiyu-pisatelya/ (in Russian).

9. Propp V.Ya. Morfologiya skazki [The morphology of the fairytale]. State Institute of the History of Arts. Leningrad, Academia Publ., 1928. 152 p. (The issues of poetics, Vol. XII). (in Russian).

Nasrtdinova V.M., Candidate of Philosophy, Associate Professor at Department of Foreign languages Kazan Higher Tank Red Banner Order of Zhukov Command School

Orenburgskiy trakt st., 6, Kazan, Russia, 420059

E-mail: vmnasrtdinova@mail.ru 